\title{
A Miniature RFID Antenna at UHF Band using Meander-Line Technique
}

\author{
Y. Gmih, Y. El Hachimi, M. Makroum' A. Farchi \\ Laboratory of Engineering, Industrial Management and Innovation, University Hassan 1st, \\ Faculty of Sciences and Technologies, Settat-Morocco
}

\begin{tabular}{l}
\hline \hline Article Info \\
\hline Article history: \\
Received Oct 23, 2017 \\
Revised Jan 8, 2018 \\
Accepted Mar 27, 2018
\end{tabular}

Keyword:
Bandwidth
Meander line
Patch
Reader
Reflection Coefficient
RFID-UHF

\begin{abstract}
This paper displays a new design of a small antenna proposed for radiofrequency identification (RFID) applications in the UHF band (ultra-high frequency). Our antenna is constituted of two rectangular patches linked together with a meander line. Using this technique reduction in antenna size of equal to $62 \%$ with respect to the conventional antenna was achieved. The antenna has a simple structure and small antenna size of $60 \times 74 \mathrm{~mm}^{2}$ or $0.18 \lambda_{\lambda 0} \times 0.226 \lambda_{\lambda 0}$. It has been fabricated on a low-cost FR4 substrate and measured to validate the simulation performances. The measured bandwidth is around $54.4 \mathrm{MHz}(889.3-943.7 \mathrm{MHz})$ with reflection coefficient less than $10 \mathrm{~dB}$, which covers all of the American RFID band (902 - $928 \mathrm{MHz})$, Chinese RFID band (920.5 - 924.5 MHz), Korea Republic and Japan RFID band ( $917-923.5 \mathrm{MHz}$ ). The design and simulations have been effected by electromagnetic simulators HFSS and CST microwave studio. A good accord is getting between the simulated and measured results. This antenna is intended for the reader of RFID applications.
\end{abstract}

Copyright @ 2018 Institute of Advanced Engineering and Science. All rights reserved.

\section{Corresponding Author:}

Yassine Gmih,

Laboratory of Engineering,

Industrial Management and Innovation,

Faculty of Sciences and Technologies,

University Hassan 1st,

Road of Casablanca, Mail Box: 577, Km 3, Settat- Morocco.

Email: yassine.gmih@gmail.com

\section{INTRODUCTION}

Radio-frequency identification, well known as RFID, is an intelligent technology system that is highly efficient, flexible and well appropriate for operations automatic. RFID is an identification method that employs radio frequency waves to capture data held in gadgets titled RFID tags. It presents various advantages compared with other identification technologies for instance barcodes. It is a contactless technology, which makes the automatic interchange of information rapid and extra efficient. It can operate under a diversity of environmental conditions, allows storing a quantity of encrypted and secured data. RFID technology employs electromagnetic fields to identify, monitor and trail objects, animals or people remotely utilize radio waves [1], [2].

An RFID radio frequency identification system typically comprises of two entities that communicate together, a smart tag and a reader. The tag linked with the element to be identified who is able to respond to a request from a reader. The latter has the task of identifying the label. It sends an electromagnetic wave to the element to be recognized. As a response, the reader obtains the information sent back by the tag.

RFID systems can be designed to operate in low-frequency (BF) to the super-high-frequency band (SHF). This operation has been standardized to keep away from any interference with another electromagnetic device [3]. The frequency bands allocated to RFID applications are a low-frequency band 
(LF: $125 \mathrm{KHz}$ ), the high frequency band (HF: $13.56 \mathrm{MHz})$, UHF band (860-960 MHz), and the microwave band $(2.45,5.8 \mathrm{GHz})[4]$, [5].

In latest years UHF RFID technology remains the most coveted in the various areas especially traceability, given its low cost and performance regarding speed and reading distance. The use of the RFID applications in UHF band is different from one country to another, according to Regulatory status for utilizing RFID in the EPC Gen2 (860 to $960 \mathrm{MHz}$ ) band of the UHF spectrum [6]. The frequency bands used are as follows: $866-869 \mathrm{MHz}$ in Europe, $902-928 \mathrm{MHz}$ in United States, 920.5 - $924.5 \mathrm{MHz}$ in China, 916.7 - 920.9 MHz and 916.7 - 923.5 MHz in Japan, 918 - 926 MHz in Australia, and 867.6 - 868 MHz in Morocco, and so on [7], [8].

Having been designated as the most indispensable components for the transmission and reception of EM electromagnetic waves, antennas play a fundamental role in the systems that use them. They remain the focal support that provides the link between the tag and the reader [9].

Over the last decades, micro strip patch antennas have been a topic of intense consideration in RFID systems, due to their several advantages [10] such as size, generally smaller than other types of antenna, low manufacturing cost, easy to fabricate [11], very flexible power supply and the choice of a polarization of the linear or circular electromagnetic wave by adjustment of the geometry and excitation of the radiating element. Much attention has been focused on miniaturizing and improving the bandwidth of patch antennas.

Some techniques have been discussed in the literature to realize the miniaturized of microstrip antennas with high performance such as changing geometry, by adding slots or notches on patch antenna [12], [13], using discrete components or adding short circuits [14], using fractal structure [15], [16], modifying ground plane (method DGS: defected ground structure), [17], [18], or miniaturization by using a high relative permittivity of the dielectric substrate, [19]. The most used technique to miniaturize the size of microstrip antennas is the folding of the dipole by meander line [20], [21]. It has important advantages; it is electrically slight, small profile antenna and has simple structure [22]. But these antennas have small radiation efficiency.

In this study, a miniaturized patch antenna founded on meander line technique at $920 \mathrm{MHz}$ is proposed for UHF band. Our antenna simply consists of a meander line with a different length of a vertical segment designed to get better bandwidth. The proposed antenna design has a small size of $60 \times 74 \mathrm{~mm}^{2}$ or about $0.184_{\lambda 0} \times 0.226_{\lambda 0}$.

The geometry of our conception will be presented in the next part of this paper. A parametric study will be demonstrated in part III and the last part will display simulated and measured results of the proposed antenna.

\section{ANTENNA DESIGN}

The design of our patch antenna founded on meander line technique is presented in this section and its geometry is exposed in Figure 1. Table 1 display the optimized dimensions of our antenna. The antenna is designed for UHF RFID applications in the frequency range of 890 - $943 \mathrm{MHz}$, it has designed and fabricated on an FR-4 substrate due to its low cost and easy fabrication with dielectric constant $\varepsilon r=4.4$, substrate height $\mathrm{h}=1.6 \mathrm{~mm}$ and loss tangent of 0.025 . The antenna is fed by microstrip line $(50 \Omega)$ via an SMA connector. The patch and the ground plane are Perfect Electric Conductor (PEC) of $0.035 \mathrm{~mm}$ of thick. The proposed antenna has smaller and compact size of only $74 \times 60 \mathrm{~mm}^{2}$ or about $0.226 \lambda_{\lambda 0} \times 0.184_{\lambda 0}$ where $\lambda_{0}$ is a freespace wavelength at $920 \mathrm{MHz}$. The results of simulation of the antenna were achieved using the software HFSS and CST.

The design of the meander lines is done by the construction and combination of lines. It's one technique of reducing the size of an antenna and can be realized by meandering vertical and horizontal lines. In case of meander line, if meander spacing is increased, resonant frequency lessens, and if meander spacing is decreased increase, resonant frequency expands. In our antenna, we try the maximum to make the space of the meander smaller according to improve the adaptation. The variation of the operating frequency by the geometrical values of the structure of meander line is described in a parametric study. Our antenna comprises of a meander in the middle of the radiating element that connects two rectangular patches with the same length, different width, and a rectangular stub inserted at the top of the feed line to improve the adaptation of the impedance. 


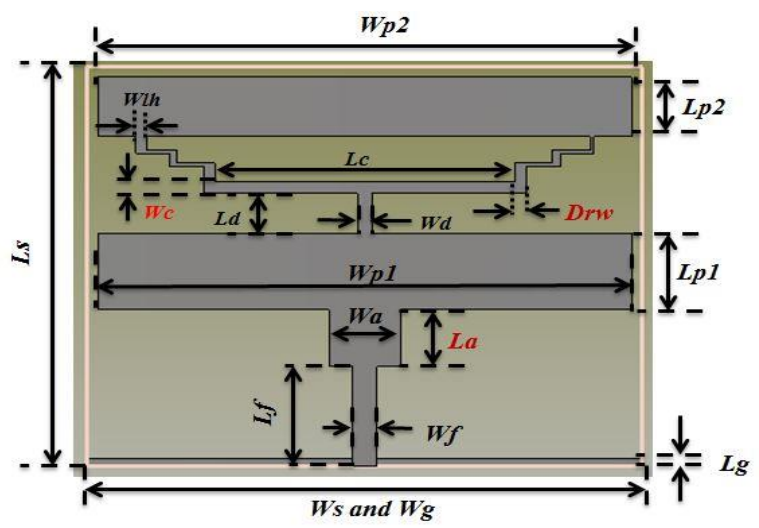

Figure 1. Geometry of the proposed antenna

Table 1. Dimensions of the Proposed Antenna

\begin{tabular}{cccc}
\hline Parameter & Value $(\mathrm{mm})$ & Parameter & Value $(\mathrm{mm})$ \\
\hline Ws \& Wg & 74 & Wp1 \& Wp2 & 71 \\
Ls & 60 & Lp1 & 11.5 \\
Lg & 1 & Wd & 2 \\
Wf & 3.2 & Ld & 6 \\
Lf & 15 & Wc & 1.7 \\
Wa & 9.5 & Lc & 40 \\
La & 8.5 & Wlh & 1.5 \\
Drw & 1.5 & Lp2 & 9 \\
\hline
\end{tabular}

\section{PARAMETRIC STUDY}

To improve the matching input impedance we have launched a study on the different parameters that can influence on the reflection coefficient at the operating frequency. After many series of optimizations, we have concluded that the La parameter is the key to ameliorate the return loss.

Figure 2 shows the impact of varying La on the impedance matching. By varying La starting from 1.5 to $8.5 \mathrm{~mm}$, the reflection coefficient S11 improves considerably from $-14 \mathrm{~dB}$ to $-44.58 \mathrm{~dB}$ and the resonant frequency shifted slightly towards center frequency $(920 \mathrm{MHz})$. From these results, as shown in Figure 2, the optimized length of the vertical line (La) is $8.5 \mathrm{~mm}$ (see also Table 2).

\subsection{The effect of the length of vertical line (La) on the impedance matching}

To improve the matching input impedance we have launched a study on the different parameters that can influence the return loss at the operating frequency. After many series of optimizations, we have deduced that the La parameter is the key to enhance the return loss.

Figure 2 shows the impact of varying La on the impedance matching. By varying La starting from 1.5 to $8.5 \mathrm{~mm}$, the reflection coefficient $\mathrm{S} 11$ improves considerably from $-14 \mathrm{~dB}$ to $-44.58 \mathrm{~dB}$ and the resonant frequency shifted slightly towards center frequency $(920 \mathrm{MHz})$. From these results, as shown in Figure 2, the optimized length of the vertical line (La) is $8.5 \mathrm{~mm}$ (see also Table 2).

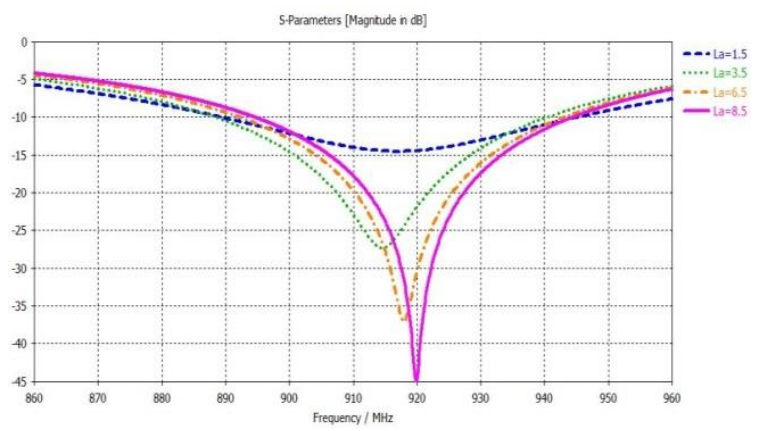

Figure 2. Simulated values of $|\mathrm{S} 11|$ of the antenna for various sizes of La 
Table 2. Effect of Changing Size of (la) on Antenna Performance Parameters

\begin{tabular}{cccc}
\hline Value of $\mathrm{La}[\mathrm{mm}]$ & $\begin{array}{c}\text { Reflection coefficient } \\
(\mathrm{S} 11)[\mathrm{dB}]\end{array}$ & $\begin{array}{c}\text { Resonant } \\
\text { Frequency }[\mathrm{MHz}]\end{array}$ & Bandwidth [MHz] \\
\hline 1.5 & -14.5 & 913.34 & $8894-944.8$ \\
3.5 & -27.3 & 914.5 & $889-939$ \\
6.5 & -37 & 918 & $892-941.7$ \\
8.5 & -44.58 & 920 & $896.1-942.5$ \\
\hline
\end{tabular}

\subsection{The effect of the width of horizontal line $(\mathrm{Wc})$ on the resonant frequency}

The plots of S11 for different values of Wc is shown in Figure 3 although the other parameters kept constant. It can be clearly seen that the return loss curves change the position of the resonant frequency with the variation of parameter Wc. In Figure 3, when Wc varies from 0.2 to $4.2 \mathrm{~mm}$, the position of the resonance frequency moves from $8867.6 \mathrm{MHz}$ to $948.8 \mathrm{MHz}$. Table 3 summarizes the bandwidth and resonances frequencies obtained by varying the Wc parameter.

Figure 3 show that good input impedance matching for the RFID bands can be obtained by tuning the values of the parameter Wc. As a result, it is observed that the other bands of RFID can be controlled simultaneously by varying the width of Wc.

According to this study on the Wc parameter, it can be seen that the variation of Wc gives us the possibility of covering different bands allocated to RFID-UHF, allowing to the regulatory status for using RFID in the EPC Gen2 (860 to $960 \mathrm{MHz}$ ) band of the UHF spectrum. When Wc lowers to $0.2 \mathrm{~mm}$, the antenna will operate well on Europe RFID Band $(865-868 \mathrm{MHz})$, when Wc takes the value of $1.7 \mathrm{~mm}$, the antenna is also adapted to the Korea RFID band $(917$ - $923.5 \mathrm{MHz})$, the Australia RFID Band (918 - $926 \mathrm{MHz}$ ) and other RFID bands like the American, Mexican and Canadian Bands (902 - $928 \mathrm{MHz}$ ), because the antenna has enough bandwidth that exceeds $50 \mathrm{MHz}$.

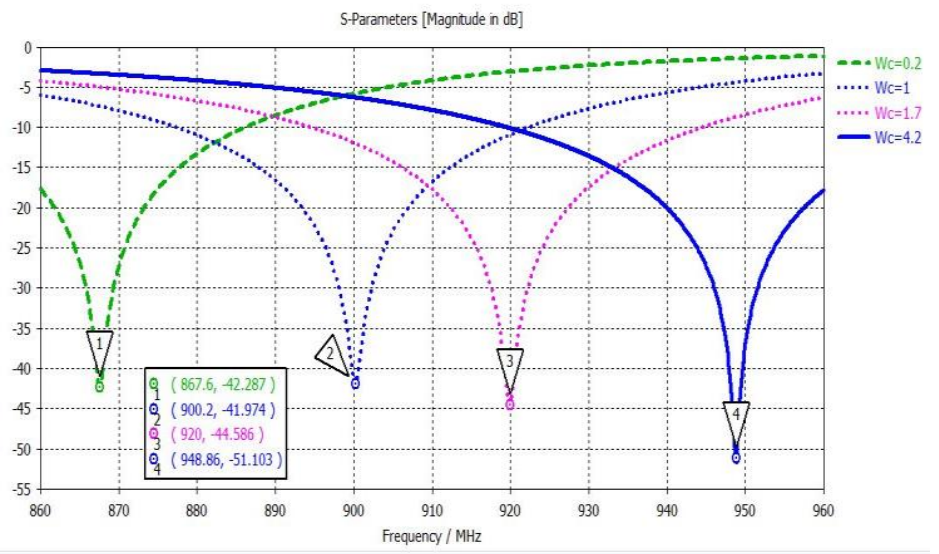

Figure 3. Simulated values of $|\mathrm{S} 11|$ of the antenna for various sizes of $\mathrm{Wc}$

Table 3. Effect of Changing Size of (Wc) on Antenna Performance Parameters

\begin{tabular}{cccc}
\hline Value of La $[\mathrm{mm}]$ & $\begin{array}{c}\text { Reflection coefficient } \\
(\mathrm{S} 11)[\mathrm{dB}]\end{array}$ & $\begin{array}{c}\text { Resonant } \\
\text { Frequency [MHz] }\end{array}$ & Bandwidth [MHz] \\
\hline 0.2 & -42.28 & 867.6 & $844-885.3$ \\
1 & -41.79 & 900.3 & $878-921$ \\
1.7 & -44.58 & 920 & $896.1-942.5$ \\
4.2 & -51.77 & 948.8 & $920-970$ \\
\hline
\end{tabular}

\subsection{The effect of the width of horizontal line (Drw) on the center resonant frequency}

The study was also carried out on another parameter important of the meander dipole; one parameter is changed, while the others kept constant. Figure 4 shows that the center frequency is increasing while the Width of Dr varies in a range when is changed from $0.5 \mathrm{~mm}$ to $2 \mathrm{~mm}$. Table 4 summarizes the bandwidth and resonances frequencies obtained by varying the Drw parameter.

This parameter slightly shifts the resonance frequency from $917.5 \mathrm{MHz}$ to $920.7 \mathrm{MHz}$ keeping the same bandwidth, its usefulness is to reach exactly the desired resonance frequency in the various RFID-UHF bands, it is enough just to vary the parameter for different values. 


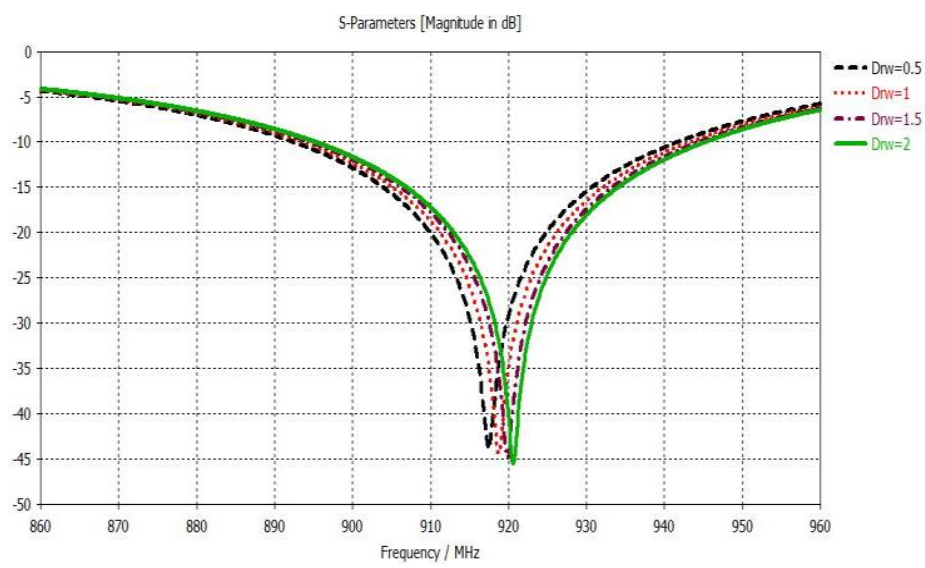

Figure 4. Simulated values of $|\mathrm{S} 11|$ of the antenna for various sizes of Drw

Table 4. Effect of Changing Size of (Drw) on Antenna Performance Parameters

\begin{tabular}{cccc}
\hline Value of La [mm] & $\begin{array}{c}\text { Reflection coefficient } \\
(\mathrm{S} 11)[\mathrm{dB}]\end{array}$ & $\begin{array}{c}\text { Resonant } \\
\text { Frequency [MHz] }\end{array}$ & Bandwidth [MHz] \\
\hline 0.5 & -43.83 & 917.5 & $892.7-940.3$ \\
1 & -44.38 & 918.76 & $895-941.6$ \\
1.5 & -44.58 & 920 & $896.1-942.5$ \\
2 & -45.21 & 920.7 & $896.5-943.5$ \\
\hline
\end{tabular}

\section{RESULTS AND DISCUSSION}

To confirm the results of the simulation, an original model of the proposed antenna is fabricated and verified. The circuit is manufactured by using LPKF machine and it is printed on the FR-4 substrate with dielectric constant of 4.4 and having a thickness of $1.6 \mathrm{~mm}$. Figure 5 shows a photograph of the fabricated antenna. The final antenna is compact, miniature and low cost, with a full size of $60 \times 74 \times 1.6 \mathrm{~mm}^{3}$. The results of simulation of the antenna were achieved using the software HFSS and CST.

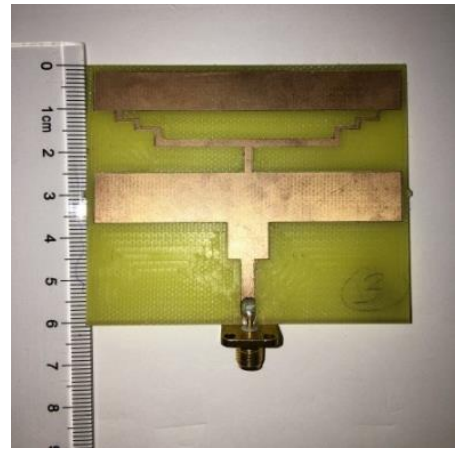

(a) Front view

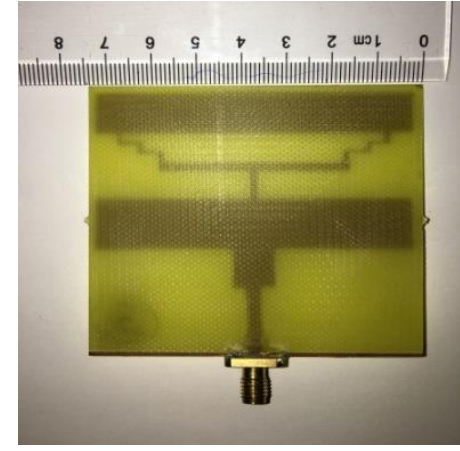

(b) Back view

Figure 5. Photographs of the fabricated antenna (a) Front view. (b) Back view.

Simulated and measured results of the return loss of the proposed antenna are shown in Figure 6 The simulated $-10 \mathrm{~dB}$ return loss bandwidth is $-44.58 \mathrm{~dB}$ at $920 \mathrm{MHz}(890-950 \mathrm{MHz})$ in CST-MS and $-37.24 \mathrm{~dB}$ at $920 \mathrm{MHz}(894.8-943 \mathrm{MHz})$ in HFSS .The measured bandwidth of the antenna prototype is $54.4 \mathrm{MHz}$ (889.3 - 943.7 MHz), under the condition of reflection coefficient less than $-10 \mathrm{~dB}$, which covers the China, Korea Rep, Japan, North and South America RFID Band (900 - $928 \mathrm{MHz}$ ) completely. In Figure 6, the antenna prototype exhibits a resonance frequency equal to $919 \mathrm{MHz}$ and a return loss of about $-25.41 \mathrm{~dB}$, which is a good result of measurement. Table 5 presents a comparison between the results of measured and simulated reflection coefficient of our miniaturized antenna. 


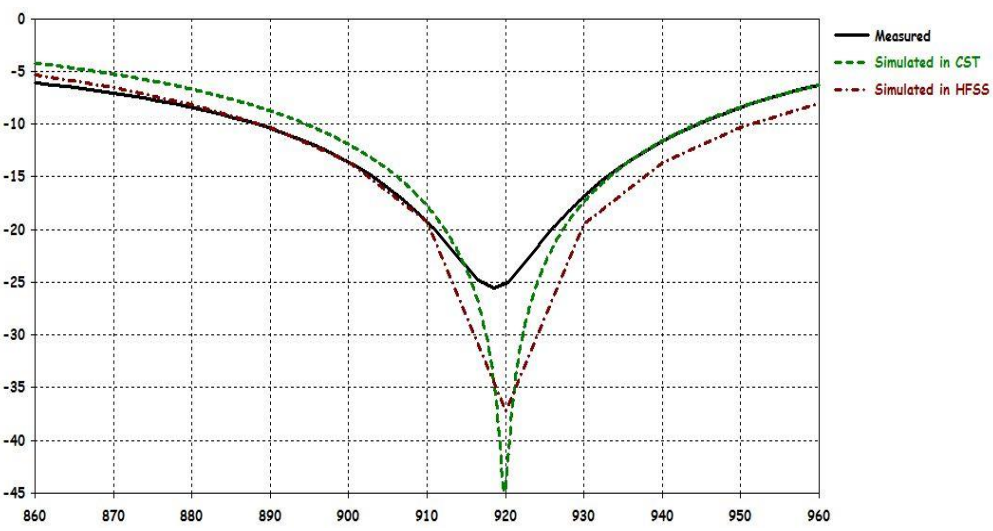

Figure 6. Simulated and measured reflection coefficient of the proposed antenna

Table 5. Comparison between the measured and simulated reflection coefficient

\begin{tabular}{cccc}
\hline & Resonant & Return loss [dB] & Bandwidth $[\mathrm{MHz}]$ \\
\hline Crequency $[\mathrm{MHz}]$ & 920 & -43.83 & 48.2 \\
HFSS & 920 & -37.24 & 60 \\
Measured & 920 & -25.41 & 54.4 \\
\hline
\end{tabular}

The experimental results demonstrate that the proposed design completely conforms with the of impedance matching obligatory on a handheld reader antenna, and the operating bandwidth with a return loss less than $-15 \mathrm{~dB}$ covers the whole allocated spectrum for UHF-RFID applications in different bands starting from 902 to $932 \mathrm{MHz}$.

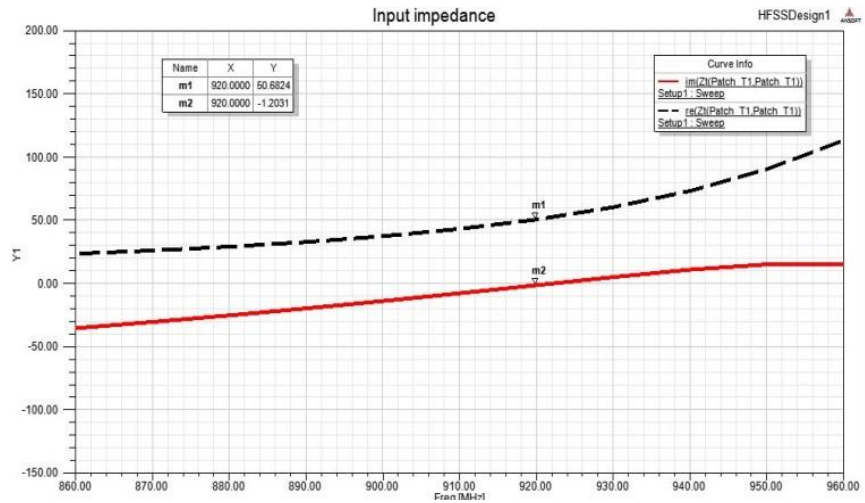

(a) HFSS

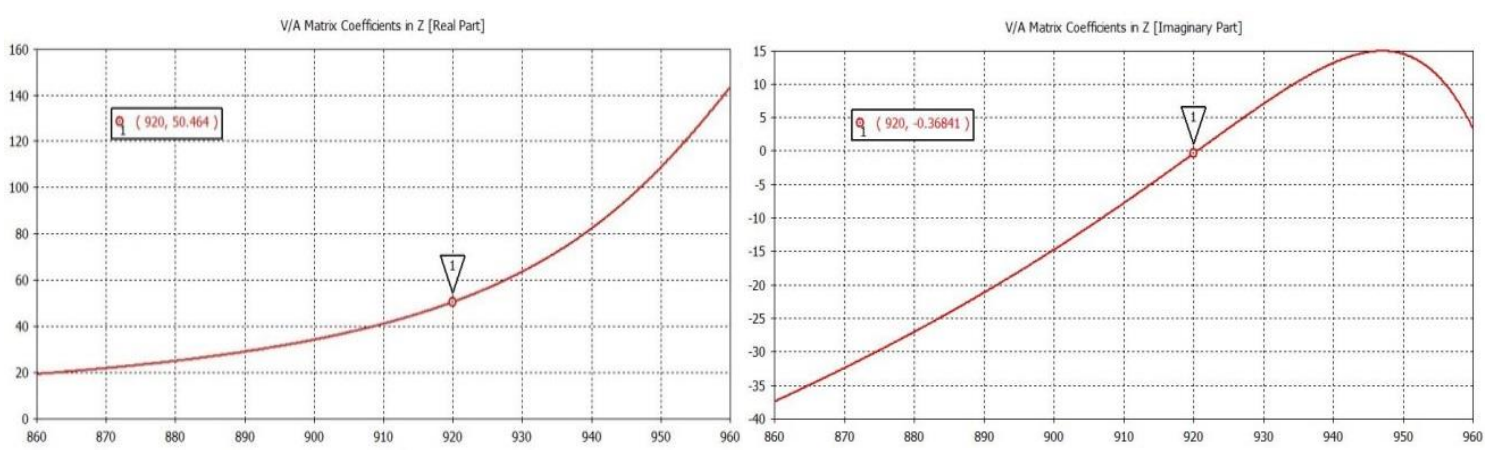

(b) CST

Figure 7. Simulated input impedance of the proposed antenna in (a) HFSS and (b) CST 
One of the important parameters that need be verified is the input impedance. In reality, this parameter reflects the adaptation of the antenna which generally allows, optimizing the transfer of electric power between the source and the load. Figure 7 appearances the variation of the input impedance.

The input impedance can be seen in Figure 7 with $\mathrm{Zin}=50.64+\mathrm{j} 0.36 \Omega$ at $920 \mathrm{MHz}$ in CT-MS and $\operatorname{Zin}=(50.68-\mathrm{j} 1.2) \Omega$ at $920 \mathrm{MHz}$ in HFSS. This proves that the antenna is adapted. Figure 8 demonstrates the simulated voltage standing wave Ratio (VSWR) of our antenna. It reaches a value of $1.01 \quad(<2)$ in CST-MS and $1.02(<2)$ in HFSS at $920 \mathrm{MHz}$ resonant frequency. The results are agreed well with each other with VSWR less than 2. This parameter can also demonstrate that our antenna is adapted.

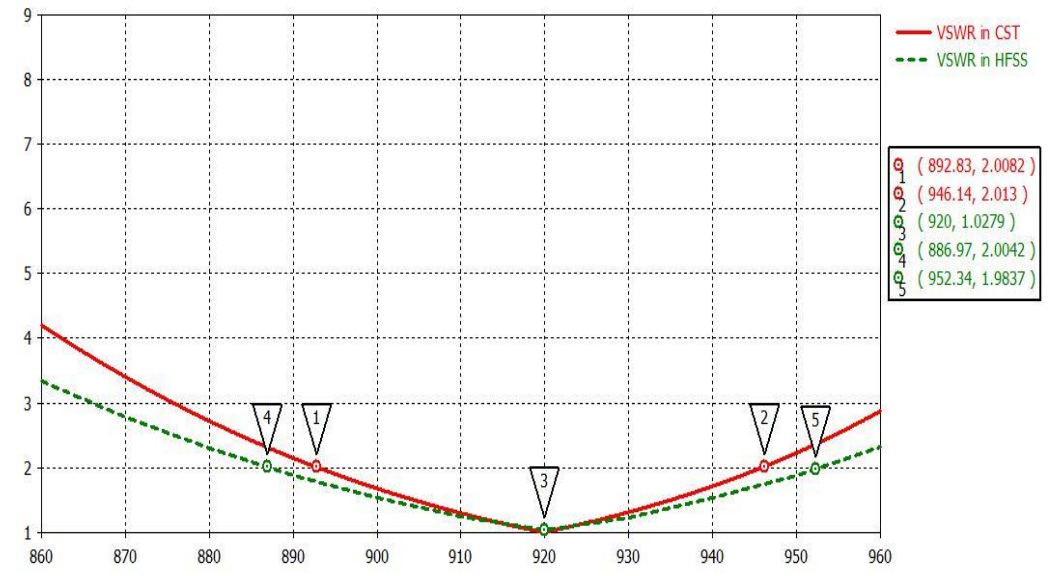

Figure 8. Simulated VSWR of the proposed antenna

Figure 9 show the radiation patterns in the $\mathrm{E}(\varphi=0 \mathrm{deg})$ and $\mathrm{H}(\varphi=90 \mathrm{deg})$ plans of the proposed antenna at the several typical frequencies $(902 \mathrm{MHz}, 920 \mathrm{MHz}$, and $928 \mathrm{MHz})$. It reflects the variation of the radiated power in different spatial directions. Note that the presented radiation pattern in the $\mathrm{E}$ and $\mathrm{H}$ plans is almost bidirectional at the resonant frequencies $902 \mathrm{MHz}, 920 \mathrm{MHz}$, and $928 \mathrm{MHz}$. It can be clearly seen in Figure 9 that a good agreement is reached between simulated results in HFSS and CST.

Figure 10 shows the simulated gain versus frequency of the proposed antenna. The gain analysis results fluctuated between 1.81 and $1.83 \mathrm{~dB}$ from 902 to $928 \mathrm{MHz}$ in HFSS and between $1.52 \mathrm{~dB}$ and 1.56 dB from 902 to $928 \mathrm{MHz}$ in CST. The simulated maximum gain of $1.83 \mathrm{~dB}$ in HFSS and $1.56 \mathrm{~dB}$ in CST was observed at $920 \mathrm{MHz}$. Meaning that our recommended antenna has a good directional characteristic, it is suitable for UHF RFID systems.

Table 6 presents comparison of the various antennas with the same substrate (FR-4 $1.6 \mathrm{~mm}$ in thick) recently reported in the literature with the proposed design for UHF RFID application in terms of size, resonant frequency, bandwidth, and gain.

Table 6. Comparison of Previous Designs with the Proposed Antenna

\begin{tabular}{ccccc}
\hline References & {$[23]$} & {$[24]$} & {$[25]$} & Proposed antenna \\
\hline Size $(\mathrm{mm})$ & $46.8 \times 74$ & $81 \times 58$ & $105 \times 90$ & $60 \times 74$ \\
Fr $(\mathrm{MHz})$ & 878 & 916 & 910 & 920 \\
Bandwidth $(\mathrm{MHz})$ & 48.83 & $25 /(905-930)$ & $26 /(902-928)$ & $54.4 /(889.3-943.7)$ \\
Gain $(\mathrm{dB})$ & -1.18 & 0.5 & 1.35 & 1.56
\end{tabular}

It is discovered that the impedance bandwidth and gain of the proposed antenna are higher compared to [23]-[25]. We can conclude that the proposed and validated antenna has a simple structure of smaller size approaching electrically small antenna, presents good performances in comparison with other structures validated in literature, and easier to fabricate. 


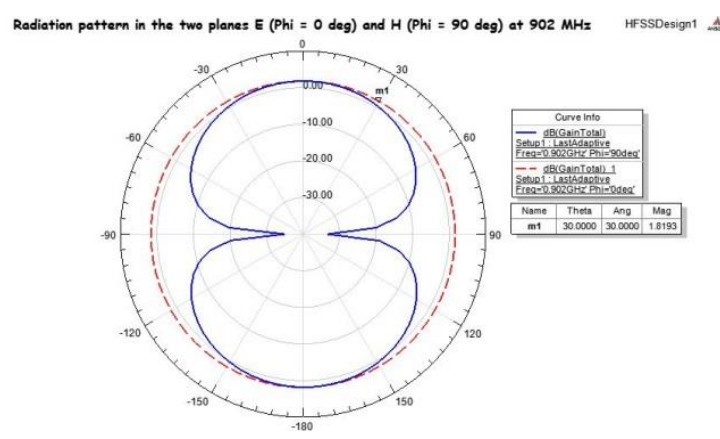

1D Results|Radiation pattern in the two planes $\mathrm{E}$ and $\mathrm{H}$ at $902 \mathrm{MHz}$

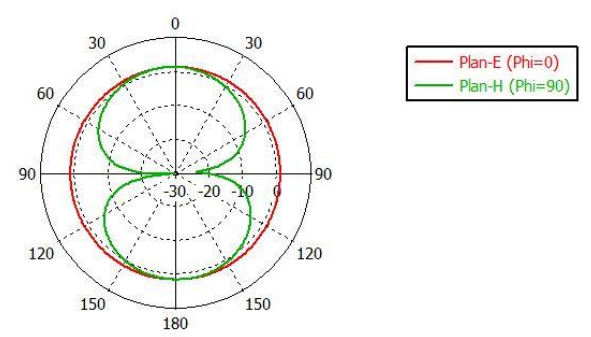

Theta / Degree vs. dB

(a)
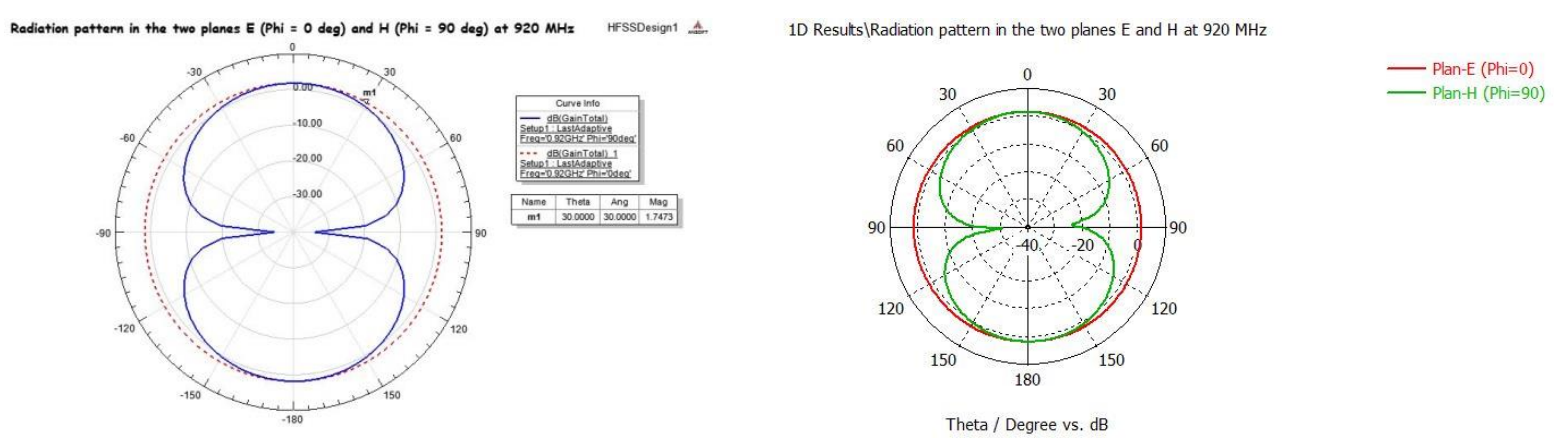

(b)

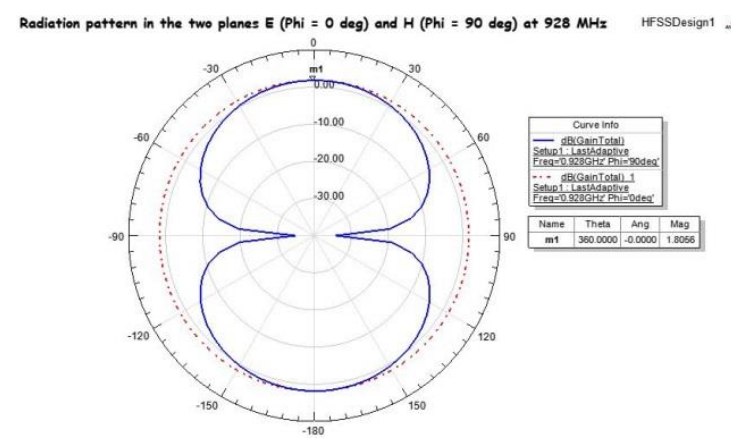

1D Results|Radiation pattern in the two planes $\mathrm{E}$ and $\mathrm{H}$ at $928 \mathrm{MHz}$
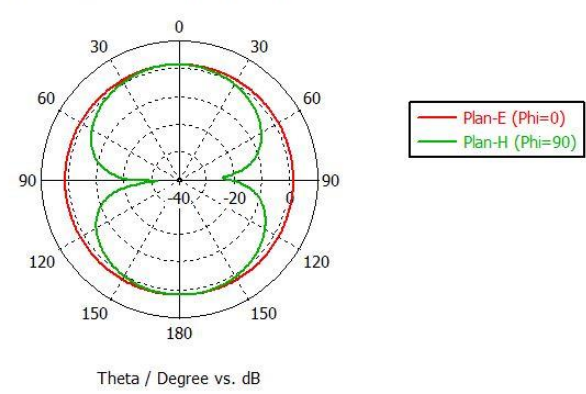

(c)

Figure 9. Simulated radiation patterns of the proposed antenna in the $\mathrm{H}$ and $\mathrm{E}$ planes at (a) $902 \mathrm{MHz}$, (b) $920 \mathrm{MHz}$, and (c) $928 \mathrm{MHz}$ in HFSS and CST

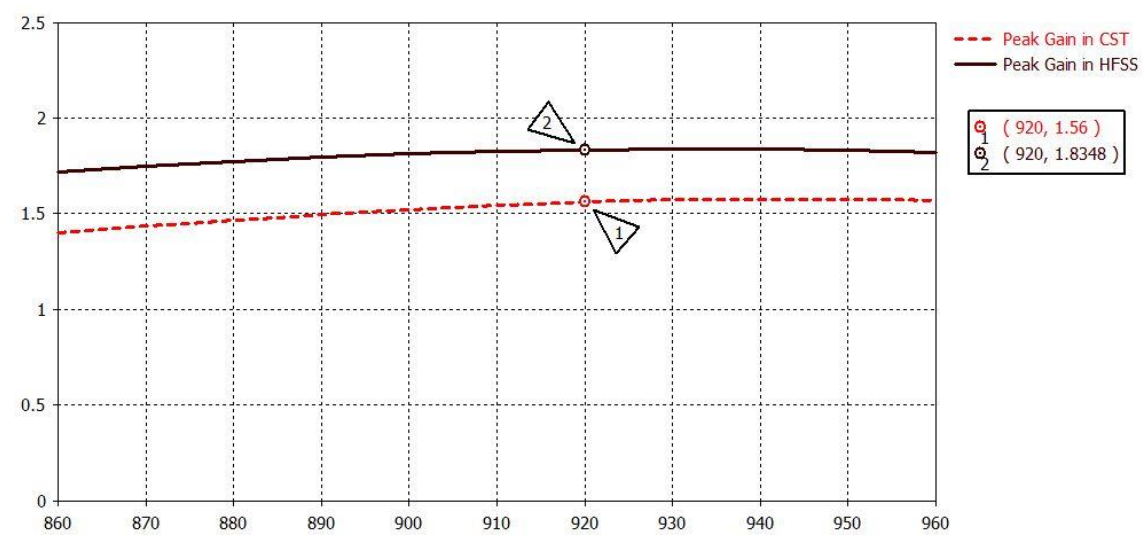

Figure 10. Simulated peak gain of the proposed antenna in HFSS and CST 


\section{CONCLUSION}

This paper research presents configuration, design theory, simulation and measurement of a novel UHF RFID reader antenna. It's based on meander line concept for UHF band applications at a resonant frequency of $920 \mathrm{MHz}$ with a bandwidth of $54 \mathrm{MHz}$, which can cover the China, Korea Rep, Japan, North and South America RFID Band (900 - $928 \mathrm{MHz}$ ) completely.

The input impedance of our antenna and its resonance frequency can be tuned by properly adjusting the parameters of the meander lines giving freedom for optimization. These parameters can be modified to handle different UHF RFID bands in this article.

Our antenna has compact dimensions of $60 \times 74 \times 1.6 \mathrm{~mm}^{3}$; a size reduction of $62 \%$ has been obtained with respect to a conventional antenna in an RFID-UHF band. Our recommended antenna is a good applicant for UHF RFID applications.

\section{REFERENCES}

[1] K. Finkenzeller, "RFID Handbook," 2nd ed. New York, NY, USA, Wiley, 2004.

[2] R. Want, “An introduction to RFID technology," IEEE Pervasive Comput., vol. 5, no. 1, pp. 25-33, 2006.

[3] D. Bechevet, "Contribution au développement de tags RFID, en UHF et micro-ondes sur matériaux plastiques," thèse doctorat de l'INPG, 2005.

[4] S. Tedjini, et al., "Radiofrequency identification system from antenna characterization to system validation," Invited paper, Asia-Pacific Microwave Conference, New Delhi, India, 2004.

[5] G. Backhouse, "RFID: Frequency, standards, adoption and innovation," JISC Technology and standards Watch, London, 2006.

[6] "Regulatory status for using RFID in the EPC Gen2 (860 to $960 \mathrm{MHz}$ ) band of the UHF spectrum," 2016.

[7] Nasimuddin, et al., "Asymmetric-circular shaped slotted microstrip antennas for circular polarization and RFID applications," IEEE Transactions on Antennas and Propagation, vol. 58, no. 12, pp. 3821-3828, 2010.

[8] R. Cao and S. C. Yu, "Wideband compact CPW-fed circularly polarized antenna for universal UHF RFID reader," IEEE Transactions on Antennas and Propagation, vol. 63, no. 9, pp. 4148-4151, 2015.

[9] I. J. Bahl and Bhartia, "Microstrip antennas design handbook," London, Artech House, 2001.

[10] J. Q. Howell, "Microstrip antennas," Dig. Int. Symp. Antennas Propagat. Soc., Williamsburg, VA, pp. 177-180, 1972.

[11] Y. Lo, et al., "Theory and experiment on microstrip antennas," IEEE Transactions on Antennas and Propagation, vol. 27, no. 2, pp. 137-145, 1979.

[12] H. T. Nguyen, et al., "Microstrip patch antenna miniaturization by slots loading," IEEE Antennas and Propagation Society International Symposium, pp. 215-218, 2005.

[13] D. Mitra, et al., "A miniaturized ring slot antenna design with enhanced radiation characteristics," IEEE Trans. Antennas Propag., vol. 64, no. 1, pp. 300-305, 2016.

[14] Z. H. Wu, et al., "A compact quad band-notched UWB monopole antenna loaded one lateral 1-shaped slot," Progress in Electromagnetics Research, vol. 139, pp. 303-315, 2013.

[15] C. Guesmi, et al., "A Modified Fractal Bow Tie Antenna for an RFID Reader," International Journal of Electrical and Computer Engineering (IJECE), vol. 4, no. 3, 2014.

[16] M. Ihamji, et al., "Design of Compact Tri-Band Fractal Antenna for RFID Readers," International Journal of Electrical and Computer Engineering (IJECE), vol. 7, no. 4, pp. 2036-2044, 2017.

[17] M. Chakraborty, et al., "Size reduction of microstrip antenna with slots and defected ground structure," International Journal of Electronics Engineering, vol. 4, no. 1, pp. 61-64, 2012.

[18] H. Elftouh, et al., "Miniaturized Microstrip Patch Antenna with Defected Ground Structure," Progress In Electromagnetics Research C, vol. 55, pp. 25-33, 2014.

[19] M. M. Ahamed, et al., "Rectangular Microstrip Patch Antenna at 2GHZ on Different Dielectric Constant for Pervasive Wireless Communication," International Journal of Electrical and Computer Engineering (IJECE), vol. 2, no. 3, pp. 417-424, 2012.

[20] C. C. Lin, et al., "A 2.4-GHz printed meander-line antenna for USB WLAN with notebook-PC housing," IEEE Microwave and Wireless Components, vol. 15, no. 9, 2005.

[21] O. O. Olaode, et al., "Effects of meandering on dipole antenna resonant frequency," IEEE Antennas Wireless Propag. Lett., vol. 11, pp. 122-125, 2012.

[22] K. Ide, et al., "Gain enhancement of low-profile, electrically small capacitive feed antennas using stacked meander lines," International Journal of Antennas and Propagation, vol. 2010, 2010.

[23] N. Ripin, et al., "A Miniaturized 878 MHz Slotted Meander Line Monopole Antenna for Ultra High Frequency Applications," Progress In Electromagnetics Research Letters, vol. 67, pp. 33-38, 2017.

[24] B. Wang, "A Compact Antenna Design for UHF RFID Applications," Progress In Electromagnetics Research Letters, vol. 53, pp. 83-88, 2015.

[25] C. Raviteja, et al., "A fractal-based circularly polarized UHF RFID reader ntenna," IEEE Antennas and Wireless Propagation Letters, vol. 13, pp. 499-502, 2014. 


\section{BIOGRAPHIES OF AUTHORS}
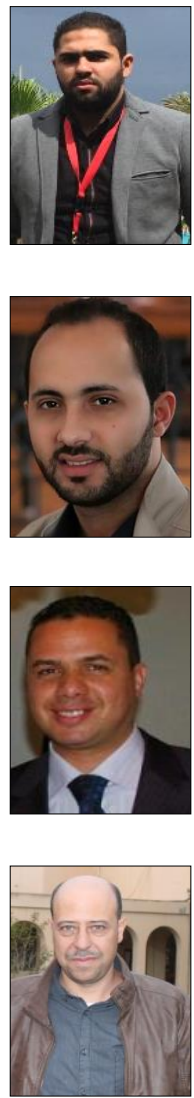

Yassine GMIH was born in 1991. He received the master degree in Automatic, Signal processing, Industrial Computing from University Hasn first, Settat, Morocco, in 2014.He is currently a PhD student in Engineering, Industrial Management and Innovation research Laboratory, Faculty of Sciences \& Technology, Hassan first University, with a thesis on Contribution to the design of RFID antennas. His research interests include antennas, UHF and microwave radiofrequency identification (RFID).

Younes EL HACHIMI was born in 1990. He received the master degree in Automatic, Signal processing, Industrial Computing from University Hassan first, Settat, Morocco, in 2014.He is currently a $\mathrm{PhD}$ student in Engineering, Industrial Management and Innovation research Laboratory, Faculty of Sciences \& Technology, Hassan first University, with a thesis on Contribution to the design of RFID antennas. His research interests include antennas, UHF and microwave radiofrequency identification (RFID).

El Mostafa MAKROUM is Professor in the faculty of the sciences and technology of Settat, Morocco. He received his M.S. degree in 2007 from the Mohammadia School of Engineering, University Mohammed V, Rabat, Morocco. He received his Ph.D. degree in Computers and Telecommunications from the Higher National School of Electricity and Mechanics, University Hassan II, Casablanca, Morocco. His current research concerns RFID antennas, propagation and EMC problems.

Abdelmajid FARCHI Ing PhD in Electronis and Telecommunications Chiefs of research team Signals and Systems in Laboratory of Engineering, Industrial Management and Innovation. Educational person responsible of the cycle engineer Telecommunications and Embedded Systems to the faculty of the sciences and technology of Settat, Morocco. 